\title{
Comportamento de vacas em lactação em pastagem manejada sob princípios agroecológicos
}

\section{Clair Jorge Olivo1, Pablo Santini Charão², Magnos Fernando Ziech², Grasiela Rossarolla², Ricardo Silveira Moraes ${ }^{3}$}

\author{
1 Departamento de Zootecnia da Universidade Federal de Santa Maria (UFSM). \\ 2 Curso de graduação em Zootecnia. \\ 3 Técnico Agrícola - UFSM.
}

RESUMO - Este estudo foi realizado com o objetivo de estudar o comportamento de vacas holandesas em lactação durante o período hibernal em pastagem constituída de capim-elefante (Pennisetum purpureum Schum.), aveia preta (Avena strigosa Schreb.) e azevém (Lolium multiflorum Lam.). As avaliações foram feitas em três ciclos de pastejo, em 17/06, 04/08 e 16/09 de 2004. Em cada avaliação, utilizaram-se seis vacas entre o 2으 e o $\underline{\underline{o}}$ mês de lactação. O registro de dados foi realizado por dois observadores das 18 às $6 \mathrm{~h}$ e das 8 às $16 \mathrm{~h}$, a cada 10 minutos. As características comportamentais observadas foram os tempos de pastejo em capim-elefante e em aveia + azevém, em pastejo total (pastejo de capim-elefante + aveia e azevém), em ruminação e ócio. Concomitantemente, avaliaram-se os dados da massa de forragem inicial, da qualidade da forragem ingerida e das condições ambientais. A maior intensidade de pastejo ocorreu após cada ordenha, verificando-se posteriormente um decréscimo, tanto durante o dia quanto à noite. Em média, o turno que os animais demandaram mais tempo de pastejo foi o diurno. O tempo destinado pelas vacas ao consumo de aveia e de azevém foi maior no período em que o capim-elefante apresentava menor porcentagem de lâminas foliares. O tempo de ócio diminuiu e o de ruminação aumentou no decorrer dos pastejos, como resultado do declínio na porcentagem de lâminas foliares e da elevação na porcentagem de colmos das espécies de ciclo hibernal. O capim-elefante foi pastejado em todas as avaliações. A presença de espécies de ciclos diferentes possibilitou aos animais equilibrarem a dieta volumosa.

Palavras-chave: aveia, azevém, capim-elefante, etologia

\section{Behavior of grazing lactating cows in agro-ecological managed pastures}

\begin{abstract}
The objective of this trial was to study the behavior of lactating Holstein cows grazing pasture containing elephantgrass (Pennisetum purpureum Schum.) and a mixture of black oat (Avena strigosa Schreb.) plus ryegrass (Lolium multiflorum Lam.). Data from six early to mid lactating cows were collected every 10 minutes interval by two observers (from 6 p.m. to 6 a.m. and from 8 a.m. to 4 p.m.) at three grazing cycles: 06/17, 08/04, and 09/16 of 2004. The following variables were measured: elephantgrass grazing time, black oat plus ryegrass grazing time, total grazing time (sum of elephantgrass and oat plus ryegrass), rumination time, and idle time. Initial herbage mass, chemical composition of ingested forage, and environmental conditions were also evaluated. Cows spent more time grazing after each milking and decreased thereafter. Diurnal grazing time was longer than nocturnal. Black oat plus ryegrass grazing time was greatest when the percentage of leaf lamina was lowest in the elephantgrass. Idle time decreased and rumination time increased during grazing cycles as a consequence of reduction in the proportion of leaf lamina and elevation on that of stems in the winter species (black oat plus ryegrass). Elephantgrass was grazed at all three grazing cycles. Availability of plant species with different growth cycles allowed animals to select a high quality forage diet.
\end{abstract}

Key Words: elephantgrass, ethology, oat, ryegrass

\section{Introdução}

Entre os fatores que afetam o comportamento de bovinos leiteiros, destacam-se o clima, a alimentação e o sistema de produção adotado (Grant \& Albright, 1995; Brâncio et al., 2003). O conhecimento das atividades desenvolvidas e dos hábitos alimentares contribui para melhoria do bem-estar
(Gonyou, 1994) e do desempenho (Fraser, 1980; Polli et al., 1995; Costa et al., 2003), tanto dos animais submetidos às condições de confinamento (Costa et al., 2003; Mendonça et al., 2004) quanto daqueles em pastejo (Brâncio et al., 2003). Especificamente para vacas em lactação, a produção, o horário e o número de ordenhas são condições determinantes em seus padrões de comportamento(Balocchi 
et al., 2002). Entre as principais variáveis comportamentais estudadas, destacam-se as relacionadas à alimentação, à ruminação e ao ócio (Ray \& Roubicek, 1971).

O tempo disponibilizado para alimentação varia de 4 a 10 horas (Fraser, 1980; Pires et al., 2001). A ingestão envolve atividades de procura, seleção, apreensão do alimento e deglutição do bolo alimentar (Fischer et al., 2002), que são mais intensas após as ordenhas (Albright, 1993).

Em condições de pastejo, as vacas apresentam comportamento típico, com picos de alimentação ao amanhecer e ao anoitecer, observando-se que esse padrão é mais intenso durante o verão. Durante o período hibernal, ocorrem pequenas variações durante o dia, maiores no turno da noite (Fraser, 1980; Balocchi et al., 2002). Normalmente, são verificados seis ciclos de pastejo por dia, quatro entre as ordenhas da manhã e da tarde e dois à noite (Albright, 1993).

Fatores como a capacidade seletiva dos bovinos em alimentar-se prioritariamente de folhas mais novas, seguidas das mais velhas e dos caules, influenciam o consumo de forragem (Stobbs, 1978). As diferenças entre forrageiras também podem afetar os hábitos alimentares dos bovinos. Normalmente, as espécies tropicais, em comparação às temperadas, tornam-se fibrosas mais rapidamente (com redução da qualidade), podendo haver limitação do consumo (Stobbs, 1973).

Em sistemas de produção de leite, orgânicos e agroecológicos, que têm como premissas a perenização e diversificação de espécies forrageiras e a liberdade de escolha dos animais, o estudo do comportamento pode contribuir tanto na avaliação das pastagens quanto no manejo a ser adotado. Sabe-se que os animais podem alterar seu comportamento ingestivo, modificando um ou mais dos seus componentes para superar condições limitantes ao consumo e obter a quantidade de nutrientes necessária (Forbes, 1988).

Em diferentes regiões do País, pastagens constituídas de capim-elefante são manejadas sob estratégia convencional. Nesta sistemática, a utilização da pastagem é feita, basicamente, no período estival, havendo rápida variação na qualidade da forragem (Townsend et al., 1995). Também têm sido citados problemas de degradação da pastagem e ataque de "pragas", que interferem na perenidade das pastagens (Dall' Agnol et al., 2004). Como é uma espécie de baixa sociabilidade e de elevado potencial de produção de massa de forragem, são necessários estudos de consorciação com outras espécies para minimizar esses problemas (Gliessman, 2000).

Pesquisas realizadas com capim-elefante em consorciação com outras espécies de mesmo ciclo produ- tivo são escassas. Questiona-se, no entanto, o comportamento do capim-elefante, especialmente se consorciado com espécies de ciclos diferentes. Considerando as características climáticas da Região Sul, a utilização de espécies anuais de ciclo hibernal em consorciação com espécies perenes de ciclo estival pode ser vantajosa tendo em vista seu uso no decorrer do ano agrícola e a racionalização dos insumos na mesma área. Pesquisas sobre o comportamento dos animais poderão apontar hábitos de pastejo e seleção dos materiais existentes, contribuindo para o estudo destes sistemas forrageiros.

Assim, objetivou-se estudar, durante o período hibernal, o comportamento de vacas em lactação em pastagem de capim-elefante, aveia e azevém manejada sob princípios agroecológicos. Foram avaliados os tempos de pastejo (do capim-elefante, da aveia + azevém e total), ruminação e ócio e, concomitantemente, foram realizados estudos associativos entre os parâmetros comportamentais e os componentes das pastagens e das variáveis ambientais.

\section{Material e Métodos}

O experimento foi conduzido no município de Santa Maria, região da Depressão Central do RS, situado a $29^{\circ} 43^{\prime}$ de latitude sul e $53^{\circ} 42^{\prime}$ de longitude oeste, com clima subtropical úmido (Moreno, 1961). A pesquisa foi realizada em pastagem manejada sob princípios agroecológicos, utilizando-se o cultivo mínimo, a consorciação de espécies e o uso de adubação orgânica (não foram usados pesticidas). Atendendo às recomendações de Mench (1998), também foram proporcionadas condições de bem-estar aos animais (disponibilidade de água e de sombra e práticas de manejo que não causassem apreensão e sofrimento aos animais).

$\mathrm{Na}$ área experimental (0,3 ha), o capim-elefante, cv. Merckeron Pinda, foi estabelecido em outubro de 2001, em camaleões feitos de forma perpendicular ao declive do terreno, com espaçamento de 3 m entre as linhas. Da implantação ao período estival de 2004 , foram conduzidas avaliações do desempenho da pastagem dentro da estratégia agroecológica com bovinos leiteiros. Nesta estratégia, foram adotados os seguintes princípios: cultivo mínimo, consorciação de espécies, uso de fertilizantes orgânicos e não-utilização de pesticidas. No período hibernal de 2004, estabeleceu-se nas entrelinhas aveia cv. Preta comum e azevém. A cada ano, a pastagem foi adubada com $150 \mathrm{~kg} / \mathrm{ha}$ de N, 70\% com chorume de suínos e 30\% com esterco bovino (coletado de piquete em descanso, armazenado e coberto com lona plástica). Desse total, $100 \mathrm{~kg}$ foram distribuídos no período estival e $50 \mathrm{~kg}$ no hibernal. 
Oestudo foi conduzido em três ciclos de pastejo distintos, entre os meses de junho e setembro de 2004. Os pastejos iniciaram-se quando a pastagem de aveia e azevém apresentava em torno de $20 \mathrm{~cm}$ de altura e finalizado quando apresentava $10 \mathrm{~cm}$. No início das avaliações, as touceiras de CE apresentavam aproximadamente $1 \mathrm{~m}$ de altura. Os ciclos de pastejo variaram de 43 a 48 dias, com período de ocupação de um dia.

Como animais experimentais, utilizaram-se seis vacas holandesas (entre o 2oㅡ o $5 \underline{0}$ mês de lactação) pertencentes ao Laboratório de Bovinocultura de Leite da Universidade Federal de Santa Maria, com peso inicial de $517 \pm 23,25 \mathrm{~kg}$ e produção de leite de $15,18 \pm 0,71 \mathrm{~kg} / \mathrm{dia}$. Cada animal recebeu diariamente como complementação alimentar $7,1 \mathrm{~kg}$ de MS (3,5 kg de concentrado com $20 \%$ de PB e 3,6 kg de MS de silagem de milho). Essa quantidade foi dividida eqüitativamente e fornecida após as ordenhas da manhã e da tarde. Os animais tiveram livre acesso à pastagem e à água durante as observações e, entre os períodos de avaliação, foram mantidos sob mesmo manejo alimentar (complementação alimentar e pastagem da época).

As características comportamentais avaliadas foram o tempo despendido em pastejo de aveia + azevém (PVZ), em pastejo do capim-elefante (PC), em pastejo total (CE mais aveia e azevém - PCVZ), em ruminação (R) e ócio (O) utilizando-se metodologia similar à adotada por Salla et al. (2003). Os dados foram registrados por dois observadores, com revezamento a cada 4 horas. As observações foram feitas a cada 10 minutos, das 18 às $6 \mathrm{~h}$ (período noturno) e das 8 às $16 \mathrm{~h}$ (período diurno), totalizando 20 horas/dia. Nas quatro horas restantes, os animais foram retirados da pastagem para a ordenha da manhã e da tarde e receberem a suplementação alimentar. Neste período, não foram feitas observações comportamentais. Os dados de comportamento diário foram agrupados (de duas em duas horas) para a constituição do etograma.

Os dados ambientais da pastagem e da produção animal, levantados concomitantemente aos das características comportamentais, foram utilizados para caracterizar o sistema de produção e efetuar a análise de correlação.

Para determinação da massa de forragem inicial da pastagem, foram feitas amostragens (quatro cortes a $50 \mathrm{~cm}$ do solo para o CE e rente ao solo para a mistura de aveia e azevém) entre 6 e 8 horas antes da entrada dos animais. As amostras foram pesadas e homogeneizadas retirando-se duas subamostras: uma foi seca em estufa para determinação do teor de MS e a outra destinada à separação botânica para estimativa da composição estrutural (para o capimelefante, a aveia e o azevém). Para estimativa da qualidade da forragem ingerida, retiraram-se, em cada avaliação, amostras de simulação de pastejo (Euclides et al., 1992), na entrada e saída dos animais da pastagem, as quais foram secas, moídas e posteriormente analisadas para determinação do teor de $\mathrm{PB}$, da digestibilidade in vitro da MS (DIVMS) e da FDN pelo método de Goering \& Van Soest (1970).

O delineamento experimental utilizado para análise da massa de forragem inicial da pastagem foi o inteiramente casualizado, com três ciclos de pastejo e quatro repetições (cortes). Os dados foram submetidos à análise de variância e ao teste Tukey a 5\% de significância para comparação de médias. As características comportamentais foram avaliadas em mesmo delineamento, com três tratamentos (épocas de pastejo) e seis repetições (vacas). Os dados foram submetidos à análise de regressão e, juntamente com os demais dados da pastagem, das variáveis ambientais e da produção animal, foram submetidos à análise de correlação pelo programa estatístico SAS (1997). O modelo matemático utilizado no delineamento foi o seguinte:

$$
\mathrm{Yij}=\mu+\mathrm{t}_{\mathrm{i}}+\varepsilon_{\mathrm{ij}}
$$

em que Yij são as variáveis dependentes; i o índice dos pastejos; $\mu$, a média geral; $\mathrm{t}_{\mathrm{i}}$, o efeito das épocas de pastejo e $\varepsilon_{\mathrm{ij}}$, o resíduo. O modelo matemático para a análise de regressão polinomial foi o seguinte:

$$
Y i j=\beta_{0}+\beta_{1} X_{i j}+\varepsilon_{i j}
$$

em que Yij são as variáveis dependentes; $\beta_{0}$, a constante da equação; $\beta_{1}$, o coeficiente de regressão; $X_{\mathrm{ij}}$, as épocas de pastejo (dias); e $\varepsilon_{\mathrm{ij}}$, o resíduo aleatório.

\section{Resultados e Discussão}

Como demonstrado na Tabela 1, a porcentagem de lâmina foliar do capim-elefante foi baixa, mas presente em todos os ciclos de pastejo. Valores mais elevados deste componente foram verificados tanto na aveia quanto no azevém, condição típica para estas espécies durante o ciclo hibernal. Apesar do equilíbrio proporcionado por estas espécies na estrutura da pastagem, houve aumento na porcentagem de colmos no decorrer da utilização, tanto da mistura das espécies anuais quanto pelo CE.

Considerando a proporção entre espécies forrageiras (dos ciclos hibernal e estival), houve maior participação do capim-elefante (MS/ha), o que não caracterizou maior acesso dos animais à pastagem, como comprovado pelos parâmetros comportamentais no segundo período de utilização. Observou-se que, de acordo com o manejo utilizado e a composição da pastagem, os animais selecionaram forragem com qualidade semelhante no decorrer dos períodos de utilização. 
Tabela 1 - Valores médios dos componentes botânicos do capim-elefante (CE), da aveia (AV), do azevém (AZ), da massa de forragem inicial, da qualidade da forragem ingerida (colhida por simulação de pastejo) e da carga animal e dados sobre as condições ambientais

Table 1 - Average values of elephantgrass (EG), black oat ( $O)$ and ryegrass (RG) botanical components, initial forage mass, chemical composition of ingested forage (grazing simulation), stocking rate and environmental conditions

\begin{tabular}{|c|c|c|c|c|}
\hline \multirow[b]{2}{*}{$\begin{array}{l}\text { Componentes botânicos (\%) } \\
\text { Botanical components }(\%) \\
\end{array}$} & \multicolumn{3}{|c|}{$\begin{array}{l}\text { Ciclo de pastejo } \\
\text { Grazing cycle }\end{array}$} & \multirow[b]{2}{*}{$\begin{array}{l}\text { Média } \\
\text { Mean }\end{array}$} \\
\hline & $17 / 06$ & $04 / 08$ & $16 / 09$ & \\
\hline Lâmina foliar (CE) (Leaf blade - EG) & 13,72 & 1,72 & 6,52 & $7,32 \pm 6,04$ \\
\hline Colmo (CE) (Stem - EG) & 45,87 & 53,85 & 43,62 & $47,78 \pm 5,37$ \\
\hline Material morto $(\mathrm{CE})($ Litter $-E G)$ & 40,41 & 44,43 & 49,86 & $44,90 \pm 4,74$ \\
\hline Lâmina foliar (AV) $(\%)$ (Leaf blade - $O$ ) & 44,63 & 19,23 & 1,44 & $21,76 \pm 21,70$ \\
\hline Colmo (AV) $($ Stem - O) & 14,01 & 22,12 & 6,47 & $14,20 \pm 7,82$ \\
\hline Lâmina foliar (AZ) (Leaf blade - $R G$ ) & 22,15 & 34,62 & 53,96 & $36,91 \pm 16,03$ \\
\hline Colmo (AZ) (Stem) (RG) & 0,65 & 2,88 & 30,22 & $11,25 \pm 16,46$ \\
\hline Lâmina foliar $\mathrm{AV}+\mathrm{AZ}$ (Leaf blade $-O+R G$ ) & 66,78 & 53,85 & 55,4 & $58,67 \pm 7,06$ \\
\hline Colmo $(\mathrm{AVZ})($ Stem $-O R G)$ & 14,66 & 25,00 & 36,69 & $25,45 \pm 11,02$ \\
\hline Material morto $\mathrm{AV}+\mathrm{AZ}($ Litter $-O+R G)$ & 10,75 & 11,06 & 7,19 & $9,66 \pm 2,15$ \\
\hline Outras espécies (Other species) & 7,82 & 10,10 & 0,72 & $6,21 \pm 4,89$ \\
\hline \multicolumn{5}{|l|}{$\begin{array}{l}\text { Massa de forragem inicial }(\mathrm{kg} / \mathrm{ha} \text { de } \mathrm{MS}) \\
\text { Initial forage mass }(\mathrm{kg} D \mathrm{DM} / \mathrm{a})\end{array}$} \\
\hline $\mathrm{CE}(E G)$ & $7.135,50^{\mathrm{a}}$ & $4.951,73^{\mathrm{a}}$ & $5.260,70^{\mathrm{a}}$ & $5782,64 \pm 1181,74$ \\
\hline $\mathrm{AV}+\mathrm{AZ}(O+R G)$ & $322,83^{\mathrm{b}}$ & $488,43^{\mathrm{ab}}$ & $754,13^{\mathrm{a}}$ & $521,79 \pm 217,58$ \\
\hline $\mathrm{CE}+\mathrm{AV}+\mathrm{AZ}(E G+O+R G)$ & $7.458,34^{\mathrm{a}}$ & $5.440,15^{\mathrm{a}}$ & $6.014,84^{\mathrm{a}}$ & $6304,44 \pm 1039,79$ \\
\hline \multirow{2}{*}{\multicolumn{5}{|c|}{$\begin{array}{l}\text { Qualidade forragem ingerida (\%) } \\
\text { Chemical composition of ingested forage (\%) }\end{array}$}} \\
\hline & & & & \\
\hline $\mathrm{PB}(C P)$ & 13,66 & 16,20 & 17,83 & $15,89 \pm 2,10$ \\
\hline $\mathrm{FDN}(N D F)$ & 48,67 & 38,84 & 39,96 & $42,49 \pm 5,38$ \\
\hline DIVMS (IVDMD) & 81,64 & 86,89 & 84,99 & $84,50 \pm 2,66$ \\
\hline $\begin{array}{l}\text { Oferta de forragem }(\mathrm{kg} \mathrm{MS} / 100 \mathrm{~kg} \mathrm{PV}) \\
\text { Forage on offer }(\mathrm{kg} D M / 100 \mathrm{~kg} \mathrm{BW})\end{array}$ & 23,21 & 26,30 & 28,00 & $25,83 \pm 1,75$ \\
\hline Carga animal instantânea (kg/ha de peso vivo) & 32.133 & 20.680 & 21.480 & $24.767 \pm 3.693,97$ \\
\hline \multicolumn{5}{|l|}{ Stocking rate $(\mathrm{kg} / \mathrm{ha}$ of $\mathrm{BW}$} \\
\hline \multicolumn{5}{|l|}{$\begin{array}{l}\text { Condições ambiental } \\
\text { Environmental condition }\end{array}$} \\
\hline $\mathrm{N}^{\circ}$. de geadas cumulativa (Number of accumulated frozen) & 4 & 9 & 13 & - \\
\hline Temperatura média/mensal $\left({ }^{\circ} \mathrm{C}\right)$ (Average monthly temperature, ${ }^{\circ} \mathrm{C}$ ) & 15,5 & 15,2 & 18,4 & - \\
\hline Temperatura média no dia $\left({ }^{\circ} \mathrm{C}\right)$ (Average daily temperature, ${ }^{\circ} \mathrm{C}$ ) & 13,3 & 26,6 & 11,54 & - \\
\hline Temperatura máxima no dia $\left({ }^{\circ} \mathrm{C}\right)$ (Daily maximum temperature,${ }^{\circ} \mathrm{C}$ ) & 20 & 30,4 & 24,8 & - \\
\hline Temperatura mínima no dia $\left({ }^{\circ} \mathrm{C}\right)$ (Minimum daily temperature, ${ }^{\circ} \mathrm{C}$ ) & 13,5 & 21,2 & 4,6 & - \\
\hline Umidade relativa (\%) no dia (Relative daily humidity, \%) & 74,5 & 52,5 & 81,5 & - \\
\hline Fotoperíodo (minutos) no dia (Photoperiod, minutes) & 150 & 228 & 630 & - \\
\hline
\end{tabular}

Médias com letras diferentes na linha diferem $(P<0,05)$ pelo teste Tukey. DIVMS = digestibilidade in vitro da matéria seca.

$D M I V D=$ dry matter in vitro digestibility;

Means with different letters in the same row differ $(P<0.05)$ by Tukey test.

A carga animal média no período total foi de $816 \mathrm{~kg}$ $\mathrm{de} \mathrm{PV} / \mathrm{ha}$, sendo maior no primeiro pastejo, quando houve maior participação do capim-elefante (massa de forragem, porcentagem de lâminas foliares). Os dados a mbientais observados encontram-se dentro das oscilações esperadas do ciclo hibernal para a região da Depressão Central (RS).

Correlações entre os componentes qualitativos e quan titativos da pastagem confirmam associações normalmente esperadas (Stobbs, 1973), como da digestibilidade in vitro da MS com o percentual de lâmina foliar do azevém $(0,9999 ; \mathrm{P}=0,0058)$ e do capim-elefante $(-0,9907$; $\mathrm{P}=0,0275)$ e da porcentagem de FDN com a massa de forragem de capim-elefante $(0,9996 ; \mathrm{P}=0,0171)$. Resultados das correlações entre os parâmetros comportamentais com as demais variáveis levantadas (Tabela 1) demonstraram que apenas o tempo destinado à ruminação apresentou associação positiva com os parâmetros da pastagem massa de forragem de aveia e azevém e a porcentagem de lâminas foliares de azevém. 
Os resultados referentes aos parâmetros comportamentais durante o período hibernal encontram-se na Tabela 2 e nas Figuras 1 e 2 . O tempo destinado ao pastejo da aveia e do azevém $(27,13 \pm 14,54 \%)$ é representado por uma equação quadrática $(\mathrm{P}=0,0001)$ com início ascendente. Para o capim-elefante $(19,20 \pm 8,70 \%)$, verificou-se o mesmo mo delo $(\mathrm{P}=0,0004)$, porém com início descendente.

Os dados levantados da pastagem no primeiro ciclo de pastejo (Tabela 1) indicam que a porcentagem de lâmina foliar das culturas de inverno foi elevada, mas a massa de forragem foi baixa. Nesse período, o capim-elefante apresentava-se com elevada massa de forragem, proporcional à época de pastejo e à área ocupada, havendo também porcentagem substancial de folhas. No ciclo de pastejo seguinte, o tempo disponibilizado para o consumo do capim-elefante foi reduzido drasticamente, ocorrendo o inverso para as culturas de inverno. Embora os valores apontem relação da porcentagem de folhas com o tempo de acesso às pastagens, não foram encontradas correlações significativas $(\mathrm{P}>0,05)$. Provavelmente, a arquitetura característica das touceiras do capim-elefante e o baixo teor de fibra nas culturas de inverno influenciaram o comportamento das vacas, que passaram a consumir não só lâminas foliares como material senescente. Parte desta última observação pode ser constatada no segundo pastejo, quando o capimelefante apresentava $1,72 \%$ de lâminas foliares. Nesta condição, nos ciclos de pastejo diário mais representativos (Figura 2), ocorridos após as ordenhas, inicialmente os animais pastejavam mais as culturas de inverno, ocorrendo em seguida equilíbrio no tempo de acesso às pastagens, mesmo que o capim-elefante apresentasse baixa porcentagem de lâmina foliar $(1,72 \%)$, em virtude de seu baixo crescimento e da ação cumulativa do frio e das geadas (Tabela 1). Neste ciclo de pastejo, as vacas disponibilizaram $9,54 \%$ do tempo para consumir o capimelefante (Tabela 2), demonstrando que os animais equilibraram sua dieta com material fibroso (Van Soest, 1994) proveniente desta cultura.

O tempo médio de pastejo total/dia nas três avaliações foi de 46,33 (6,26\% - 9 horas e 16 minutos), semelhante ao encontrado por Phillips \& Rind (2001) em vacas holandesas em pastejo de azevém perene recebendo suplementação com $2 \mathrm{~kg} / \mathrm{dia}$ de concentrado (33,08\% - 8 horas e 9 minutos/dia). Tempos de pastejo menores foram encontrados, ambos em 24 horas de observação, por Pires et al. (2001), de 32,5\% ( 7 horas e 48 minutos), em vacas lactantes em pastagem de coastcross (Cynodon dactylon), sem suplementação; e Orr et al. (2001), de 32,08\% (7 horas e 42 minutos), utilizando vacas holandesas em pastagem de azevém perene sob suplementação com $4 \mathrm{~kg}$ de concentrado/dia.

A variabilidade nos tempos de pastejo observada entre as pastagens, confirmada pelos elevados coeficientes de variação e pelos modelos matemáticos (curvilíneos) encontrados, contrasta com a análise dos valores referentes ao pastejo total, no qual verificou-se baixa variabilidade, sendo o modelo quadrático $(\mathrm{P}=0,0168)$ ascendente (Figura 1). Essa tendência de as vacas dispensarem mais tempo no 20 e no 30 pastejos deve-se, possivelmente, à maturação do azevém e, de forma mais intensa, da aveia, além da elevada quantidade de material senescente entre as brotações do capim-elefante (Tabela 1).

Os resultados obtidos, considerando o manejo adotado (altura de resíduo de pós-pastejo da pastagem de inverno), demonstram que o capim-elefante representa alternativa de

Tabela 2 - Tempo utilizado pelas vacas em lactação (\%), em 20 horas diárias, nas atividades de ruminação (R), ócio (O), pastejo de aveia e azevém (PVZ), pastejo de capim-elefante (PC), pastejo total (pastejo de capim-elefante + aveia e azevém - PCVZ), pastejo diurno (PD) e pastejo noturno (PN)

Table 2 - Time spent by lactating cows, expressed as percentage of 20 hours of data collection, at activities of rumination ( $R$ ), idle $(I)$, and grazing black oat plus ryegrass (ORGG), elephantgrass (EGG), total grazing (sum of elephantgrass and black oat plus ryegrass - TG), diurnal grazing (DG), and nocturnal grazing (NG)

\begin{tabular}{|c|c|c|c|c|c|}
\hline \multirow[b]{2}{*}{$\begin{array}{l}\text { Característica comportamental } \\
\text { Behavior parameters }\end{array}$} & \multicolumn{3}{|c|}{$\begin{array}{l}\text { Ciclo de pastejo } \\
\text { Grazing cycle }\end{array}$} & \multirow[b]{2}{*}{$\begin{array}{l}\text { Média } \\
\text { Mean }\end{array}$} & \multirow[b]{2}{*}{$\begin{array}{c}\text { Coeficiente de variação } \\
\text { Coefficient of variation }\end{array}$} \\
\hline & $17 / 06$ & $04 / 08$ & $16 / 09$ & & \\
\hline $\mathrm{R}(R)$ & 24,327 & 27,135 & 32,353 & $27,938 \pm 5,69$ & 16,98 \\
\hline $\mathrm{O}(I)$ & 36,354 & 21,488 & 19,328 & $25,723 \pm 10,14$ & 26,87 \\
\hline $\operatorname{PVZ}(O R G G)$ & 12,644 & 41,736 & 27,031 & $27,137 \pm 13,50$ & 22,52 \\
\hline $\mathrm{PC}(E G G)$ & 26,674 & 9,642 & 21,289 & $19,202 \pm 9,10$ & 30,01 \\
\hline $\operatorname{PCVZ}(T G)$ & 39,319 & 51,377 & 48,319 & $46,339 \pm 8,12$ & 14,21 \\
\hline $\operatorname{PD}(D G) *$ & 55,449 & 54,531 & 57,680 & $55,887 \pm 1,62$ & - \\
\hline $\operatorname{PN}(N G) *$ & 44,551 & 45,469 & 42,320 & $44,113 \pm 1,62$ & - \\
\hline
\end{tabular}

*Dados não analisados estatisticamente.

*Data not analyzed statistically. 


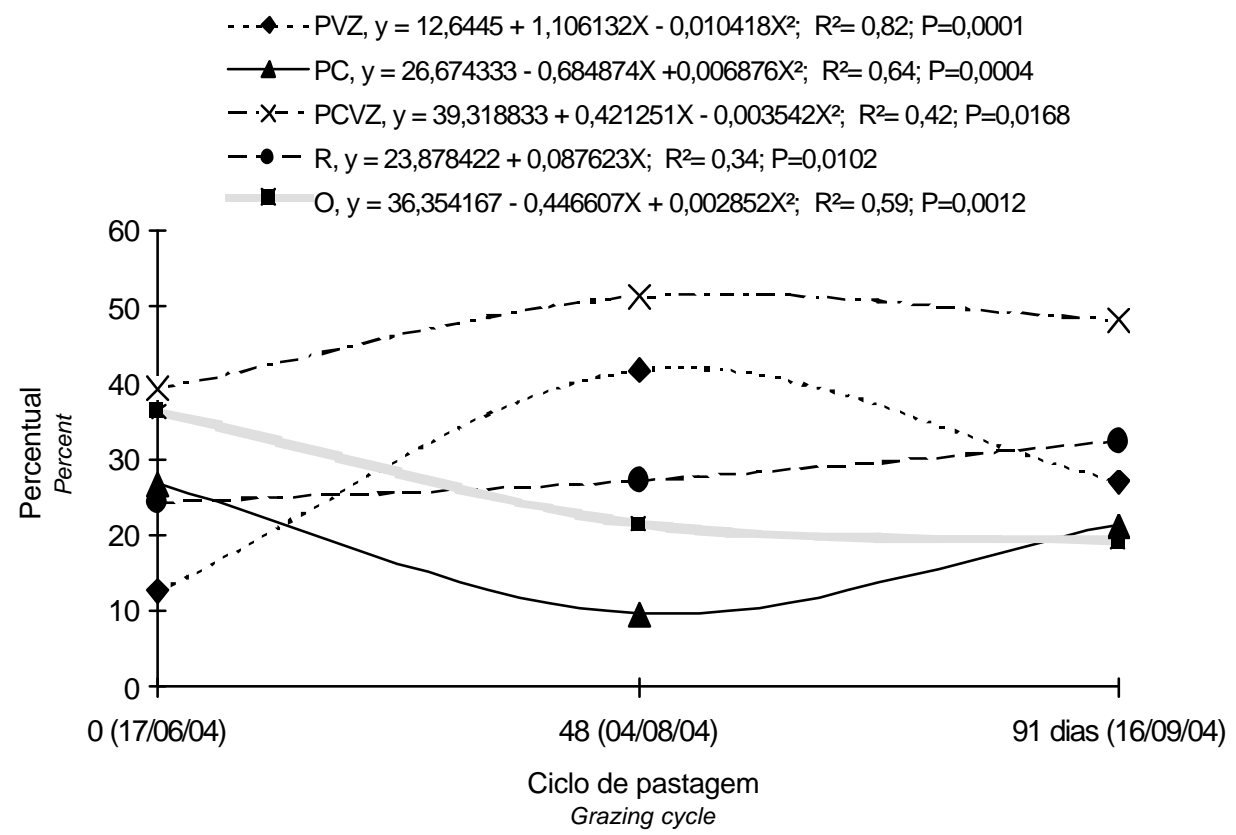

Figura 1 - Dados percentuais das características comportamentais tempo de pastejo de aveia + azevém (PVZ), tempo de pastejo de capim-elefante (PC), tempo de pastejo total (soma do tempo de pastejo do capim-elefante e aveia + azevém - PCVZ), ruminação $(\mathrm{R})$ e ócio $(\mathrm{O})$ de vacas holandesas em lactação.

Figure 1 - Percentage of time spent by lactating Holstein cows grazing black oat plus ryegrass (PVZ), elephantgrass (PC), total grazing (sum of elephantgrass and oat plus ryegrass - PCVZ), rumination (R), and idle (O).

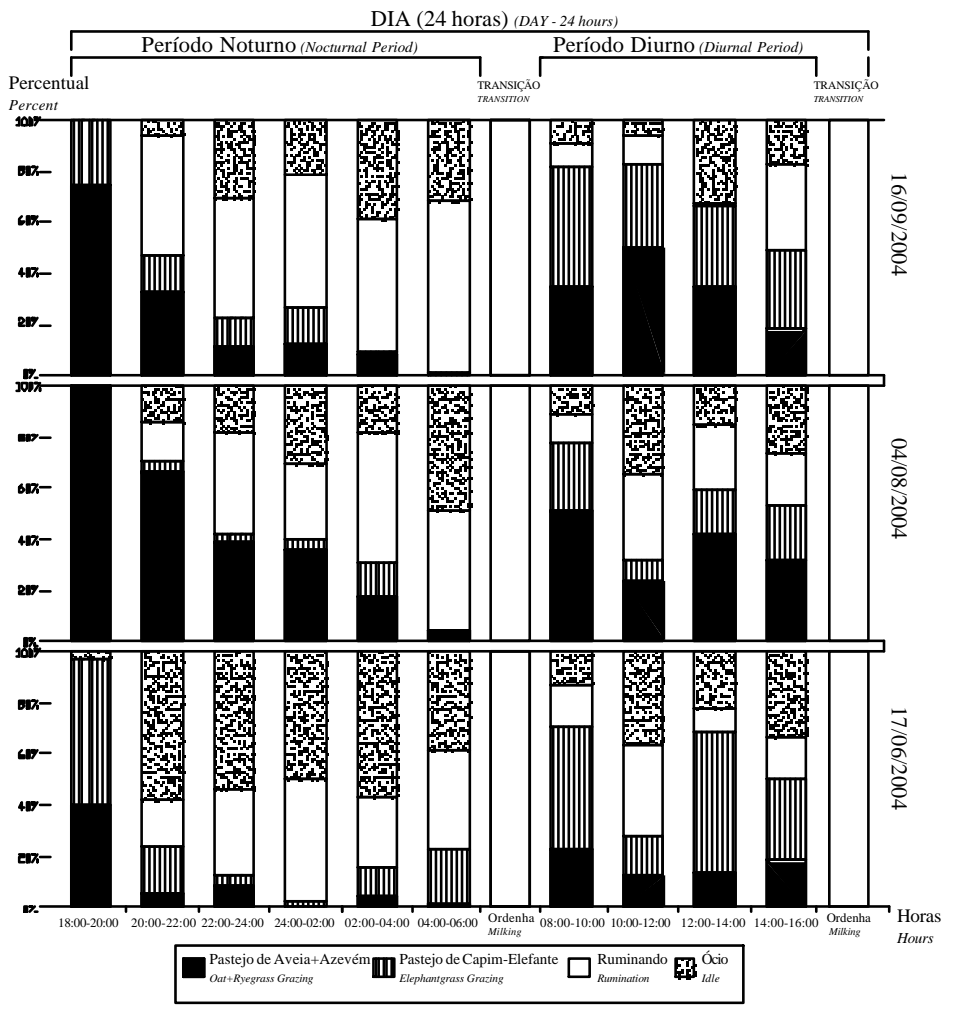

Figura 2 - Tempo médio gasto por vacas em lactação (percentual do tempo em 20 horas) em três diferentes períodos da estação hibernal. Dados agrupados em intervalos de duas horas, com os animais em pastagem de capim-elefante (Pennisetum purpureum), aveia preta (Avena strigosa) e azevém (Lolium multiflorum).

Figure 2 - Average time spent by lactating cows (percentage of time in 20 hours) at three different periods of the winter season. Data were grouped in two hours intervals with animals grazing elephantgrass (Pennisetum purpureum) and a mixture of black oat (Avena strigosa) plus ryegrass (Lolium multiflorum). 
consorciação forrageira também para o período hibernal (na Região Sul do Brasil), no qual ocorrem deficiências de disponibilidade e de qualidade de forragem para o gado leiteiro, especialmente no outono e no início da primavera.

$\mathrm{O}$ aumento do tempo de pastejo com o decorrer das avaliações implicou em aumento significativo $(\mathrm{P}=0,0102)$ da ruminação e em diminuição $(P=0,0012)$ do ócio, o que pode ser explicado, em parte, pela maturação da aveia e do azevém, confirmado pela associação significativa $(0,9992$; $\mathrm{P}=0,0243$ ) entre o tempo de ruminação e a massa de forragem destas espécies.

$\mathrm{O}$ valor médio do tempo de ruminação encontrado, de $27,93 \pm 4,07 \%$ ( $5 \mathrm{~h}$ e $35 \mathrm{~min}$ ), foi inferior aos obtidos por Balocchi et al. (2002), que observaram variação de 7 horas e 20 minutos a 7 horas e 30 minutos, em 24 horas de observação, ao trabalharem com vacas em lactação sob pastagem de azevém perene e complementação de $6 \mathrm{~kg} / \mathrm{dia}$ de concentrado. O tempo de ruminação de 4 a 9 horas/dia encontra-se na faixa normalmente verificada em bovinos (Fraser, 1980; Van Soest, 1994). Os valores não ultrapassaram o limite de 9 horas/dia apontado por Welch \& Hooper (1982). As análises de correlação demonstraram que este parâmetro apresentou associação positiva com a porcentagem de lâmina foliar do capim-elefante $(0,9992 ; \mathrm{P}=0,0245)$, condição esperada, tendo em vista a maior quantidade de FDN das culturas de ciclo estival(Van Soest, 1994). Houve associação também com a porcentagem de lâmina foliar do azevém $(0,9988 ; \mathrm{P}=0,0303) \mathrm{e}$, embora essa relação não fosse esperada, no decorrer dos pastejos, houve aumento da biomassa disponível (kg de MS de lâminas foliares) e da altura de plantas do azevém. Nesta condição, os animais tendem a diminuir o tempo de pastejo e elevar o de ruminação; ou menor biomassa, os animais tendem a selecionar mais a dieta e destinar mais tempo à procura de forragem, diminuindo, conseqüentemente, o tempo de ruminação (Trevisan, 2004).

O tempo de ócio foi de $25,72 \pm 9,26 \%$, apresentando comportamento quadrático descendente $(\mathrm{P}=0,0012)$ no decorrer das avaliações (Figura 1). O valor encontrado (5 horas e 8 minutos) foi inferior aos observados por Phillips $\&$ Rind (2001), de 9 horas e 17 minutos, e por Orr et al. (2001), de 9 horas e 5 minutos, nas 24 horas do dia. O maior tempo de ócio foi observado no primeiro ciclo de pastejo e coincidiu com a maior participação de lâminas foliares das culturas anuais de inverno (aveia + azevém) e do capimelefante e, consequientemente, com a maior biomassa disponível (Tabela 1).

Comparando os turnos (Tabela 1 e Figura 2), nota-se que as vacas destinaram maior tempo para o pastejo diurno $(55,8 \pm 1,61 \% ; 5$ horas e 10 minutos $)$, o que está de acordo com o previsto para climas temperados, segundo Pires et al. (2001), que verificaram valor de $65,2 \%$ (5 horas e 5 minutos) para o pastejo diurno (período entre 6 e 17 horas), semelhante ao encontrado por Albright (1993), de aproximadamente $66 \%$. Os valores, no entanto, foram inferiores aos encontrados por Balocchi et al. (2002). O tempo de pastejo noturno representou $44,11 \pm 1,61 \%$ ( 4 horas e 5 minutos) e foi superior ao encontrado por Pires et al. (2001), que verificaram 34,6\% (2 horas e 42 minutos) e por Balocchi et al. (2002), que observaram valores entre 16,6 (1 hora e 14 minutos) e $12,8 \%$ ( 1 hora e 3 minutos).

Nos dados de comportamento diário dos animais, agrupados a cada duas horas (Figura 2), observaram-se dois pastejos típicos, um após a ordenha da manhã e outro após a da tarde. Depois desses ápices de pastejo, sucederam-se picos de menor intensidade. Em todos os ciclos de pastejo, as vacas disponibilizaram mais tempo durante o dia, mesmo no segundo, no qual a temperatura registrada foi bem superior à média mensal (Tabela 1). Os animais disponibilizaram mais tempo para o pastejo de CE durante o dia $(66,88 \%)$ que à noite $(33,12 \%)$, provavelmente em virtude da maior facilidade para selecionar as folhas em meio às touceiras de CE (apresentavam elevada quantidade de material morto), favorecida pela luz do dia. Os dados agrupados demonstram que os animais pastejaram durante todo o dia, alternando períodos de maior e menor tempo de pastejo com as demais atividades. À noite, esse comportamento se repetiu, mas com menor intensidade, havendo um horário em que os animais praticamente não pastejaram, de meia-noite às $2 \mathrm{~h}$ na primeira e das 4 às $6 \mathrm{~h}$ para a segunda $\mathrm{e}$ a terceira avaliação, respectivamente. As oscilações observadas durante a noite (Figura 2) confirmam que há maior variabilidade no comportamento dos animais em relação ao dia (Balocchi et al., 2002). O aumento no tempo de pastejo entre o primeiro e os demais ciclos de pastejo deve-se, possivelmente, à necessidade dos animais em selecionar a dieta, tendo em vista a diminuição do percentual de lâminas foliares e o aumento do percentual de colmos (Tabela 1).

\section{Conclusões}

Com base no sistema forrageiro proposto e no manejo dos animais, observaram-se dois períodos típicos de pastejo (após as ordenhas da manhã e da tarde), verificando-se outros de menor intensidade, tanto durante o dia quanto à noite. Comparando-se os turnos, os animais pastejaram mais durante o dia.

O tempo destinado pelas vacas ao consumo de aveia e de azevém foi maior no período em que o capim-elefante apresentou menor porcentagem de lâminas foliares. Inde- 
pendentemente das épocas avaliadas, típicas do período hibernal, os animais pastejaram o capim-elefante.

O tempo de ócio diminuiu e o de ruminação aumentou no decorrer dos pastejos, como resultado do declínio na porcentagem de lâminas foliares e da elevação na porcentagem de colmos das espécies de ciclo hibernal.

O sistema proposto, baseado em princípios agroecológicos e constituído por capim-elefante, aveia e azevém, proporcionou equilíbrio na massa de forragem inicial.

A presença de espécies forrageiras de ciclos hibernal e estival proporcionou aos animais condições para a ingestão de dieta equilibrada em termos de fibra em detergente neutro e digestibilidade in vitro da MS.

O comportamento das vacas, em função do manejo proposto, demonstrou que o capim-elefante pode ser utilizado em consorciação com aveia e azevém durante o período hibernal.

\section{Literatura Citada}

ALBRIGHT, J.L. Nutrition and feeding calves: feeding behavior of dairy cattle. Journal of Dairy Science, v.76, n.2, p.485498,1993

BALOCCHI, O.; PULIDO, R.; FERNÁNDEZ, J. Comportamiento de vacas lecheras en pastoreo com y sin suplementación com concentrado. Agricultura Técnica, v.62, n.1, p.87-98, 2002.

BRÂNCIO, P.A.; EUCLIDES, V.P.B; NASCIMENTO JR., D. et al. Avaliação de três cultivares de Panicum maximum Jacq. sob pastejo: comportamento ingestivo de bovinos. Revista Brasileira de Zootecnia, v.32, n.5, p.1045-1053, 2003.

COSTA, C.O.; FISCHER, V.; VETROMILLA, M.A.M. et al. Comportamento ingestivo de vacas Jersey confinadas durante a fase inicial da lactação. Revista Brasileira de Zootecnia, v.32, n.2, p.418-424, 2003.

DALL'AGNOL, M.; SCHEFFER-BASSO, S.M.; NASCIMENTO, J.A.L. et al. Produção de forragem de capim-elefante sob clima frio. Curva de crescimento e valor nutritivo. Revista Brasileira de Zootecnia, v.33, n.5, p.1110-1117, 2004.

EUCLIDES, V.P.B.; MACEDO, M.C.M.; OLIVEIRA, M.P. Avaliação de diferentes métodos de amostragens sob pastejo. Revista Brasileira de Zootecnia, v.21, n.4, p.691-702, 1992.

FISCHER, V.; DESWYSEN, A.G.; DUTILLEUL, P. et al. Padrões da distribuição nictemeral do comportamento ingestivo de vacas leiteiras, ao início e ao final da lactação, alimentadas com dieta à base de silagem de milho. Revista Brasileira de Zootecnia, v. 31, n.5, p. $2129-2138,2002$.

FORBES, T.D.A. Researching the plant-animal interface: The investigation of ingestivo behavior in grazing animal. Journal of Animal Science, v.66, p.2369-2379, 1988.

FRASER, A.F. Comportamiento de los animales de la granja. Zaragoza: Acribia, 1980. 291p.

GLIESSMAN, S. Agroecologia: Processos ecológicos em agricultura sustentável. Porto Alegre: Universidade Federal de Porto Alegre, 2000. 401p.

GOERING, H.K.; Van SOEST, P.J. Forage fiber analyses, apparatus, reagents, procedures and some applications (Agricultural Handbook). Washington, D.C.: USDA, 1970. 379p. GONYOU, H.W. Why the study of animal behavior is associated with the animal welfare issue. Journal of Animal Science, v.72, n.8, p.2171-2177, 1994

GRANT, R.J.; ALBRIGHT, J.L. Feeding behaviour and management factors during the transition period in dairy cattle. Journal of Animal Science, v.73, n.9, p.2791-2803, 1995.

MENCH, J.A. Farm animal welfare. In: BEKOFF, M. (Ed.) Encyclopedia of animal rights and animal welfare. Connecticut: Greenwood Press, 1998. p.170-171.

MENDONÇA, S.S.; CAMPOS, J.M.S; VALADARES FILHO, S.C et al. Comportamento ingestivo de vacas leiteiras alimentadas com dietas a base de cana-de-açúcar ou silagem de milho. Revista Brasileira de Zootecnia, v.33, n.3, p.723-728, 2004.

MORENO, J.A. Clima do Rio Grande do Sul. Porto Alegre: Secretaria da Agricultura, 1961.41p.

ORR, R.J.S.; RUTTER, S.M.; PENNING, P.D. et al. Matching grass supply to grazing patterns for dairy cows. Grass and Forage Science, v.56, n.35, p.352-361, 2001.

PHILLIPS, C.J.; RIND, M.I. The effects of social dominance on the production and behavior of grazing dairy cows offered forage supplements. Journal of Dairy Science, v.85, n.1, p.51-59, 2001.

PIRES, M.F.A.; VILELA, D.; ALVIM, M.J. Comportamento alimentar de vacas holandesas em sistemas de pastagens ou em confinamento. Coronel Pacheco: Embrapa Gado de Leite, 2001. 2p. (Boletim Técnico, 2).

POLLI, V.A.; RESTLE, J.; SENNA, D.B. et al. Comportamento de bovinos e bubalinos em regime de confinamento. I Atividades. Ciência Rural, v.25, n.1, p.127-131, 1995.

RAY, D.E.; ROUBICECK, C.B. Behaviour of feedlot cattle during two seasons. Journal of Animal Science, v.33, n.1, p.46-51, 1971.

SALLA, L.E.; FISCHER, V.; FERREIRA, E.X. et al. Comportamento ingestivo de vacas jersey alimentadas com dietas contendo diferentes fontes de gordura nos primeiros 100 dias de lactação. Revista Brasileira de Zootecnia, v.32, n.3, p. 683-689, 2003.

STATISTICAL ANALYSIS SYSTEM - SAS User's Guide. 2.ed. Cary: 1997. 456p.

STOBBS, T.H. The effect of plant structure on the intake of tropical pasture. 2. Differences in sward structure, nutritive value, and bite size of animals grazing Setaria anceps and Chloris gayana at various stages of growth. Australian Journal of Agricultural Research, v.24, n.6, p.821-829, 1973.

STOBBS, T.H. Milk production, milk composition, rate of milking and grazing behavior of dairy cows grazing two tropical grass pasture under a leader and follower systems. Australian Journal of Experimental Agriculture and Animal Husbandry, v. 18 , n.1, p.5-11, 1978 .

TREVISAN, N.B.; QUADROS, F.L.F.; SILVA, A.C.F et al. Comportamento ingestivo de novilhos de corte em pastagem de aveia preta e azevém com níveis distintos de folhas verdes. Ciência Rural, v.34, n.5, p.1543-1548, 2004.

TOWNSEND, C.; OLIVO, C.J.; RUVIARO, C.F. et al. Valor nutritivo de cultivares de capim-elefante (Pennisetum purpureum Schum.) sob condições de pastejo. Ciência Rural, v.25, n.1, p.121-126, 1995.

Van SOEST, P.J. Nutritional ecology of the ruminant. Ithaca: Cornell University, 1994. 476p.

WELCH, J.G.; HOOPER, A.P. Ingestion de alimentos y agua. In: CHURCH, D.C. (Ed.) El rumiante: fisiologia digestiva y nutrición. Zaragoza: Acribia, 1982. p.117-126. 